\title{
Electrocardiographic Studies on Extra-Cardiac Affections in Dogs
}

\author{
Moneesh Thakur ${ }^{1 *}$, S.R. Upadhyay ${ }^{1}$ and Radhika Thakur ${ }^{2}$ \\ ${ }^{1}$ Division of Veterinary Medicine, Faculty of Veterinary Sciences and Animal Husbandry \\ R.S. Pura, SKUAST-Jammu \\ ${ }^{2}$ Departemnt of Basic Sciences, College of Forestry, Dr. Y.S. Parmar University of \\ Horticulture \& Forestry, Nauni, Solan, Himachal Pradesh-173230 \\ *Corresponding author
}

\section{Keywords}

ECG, Extra-Cardiac

Diseases,

Gastroenteritis,

Urinary Tract

Diseases, Dog.

Article Info

Accepted:

08 July 2018

Available Online:

10 August 2018

\section{A B S T R A C T}

The present study was conducted to investigate characteristics of electrocardiography in gastroenteritis (GE) and urinary tract diseases (UTD) in dogs. The positive cases of GE (Group B) and UTD (Group C) affected dogs were screened for ECG and haematobiochemical parameters as per the standard procedure and the outcome was compared and correlated statistically with healthy dogs (Group A). A decreased in amplitude of P wave, $\mathrm{T}$ wave and QRS complex were observed in both the affected groups (Gr. B \& C) as compared to Group A. Additionally, a significant $(\mathrm{P}<0.05)$ decreased in $\mathrm{Hb}, \mathrm{PCV}, \mathrm{TEC}$, $\mathrm{MCHC}$ and TP and increased in AST and ALT were also noted in Group B whereas decreased $\mathrm{Hb}$ and TEC and increased in BUN, Creatinine and ALP were observed in Group C. There was significant $(\mathrm{P}<0.05)$ positive and negative correlations between Electrocardiogram and haemato-biochemical parameters were observed in both the affected groups. The study revealed that ECG and haemato-biochemical parameters had a significant role in extra-cardiac diseases i.e. gastroenteritis as well as urinary tract diseases in dogs.

\section{Introduction}

Electrocardiography, a non-invasive and relatively inexpensive technique has now generally been accepted as an important diagnostic tool in detecting cardiac abnormalities in dogs (Tilley, 1985). It detects not only the disturbances of cardiac rate and rhythm but also cardiac enlargement, myocardial disease, ischemia, pericardial diseases, certain electrolyte imbalances and some drug toxicities. The electrocardiogram is a basic and valuable diagnostic test in veterinary medicine and is relatively easy to acquire. The electrocardiogram is the initial test of choice in the diagnosis of cardiac arrhythmias and may also yield information regarding chamber dilation and hypertrophy. Electrocardiography (ECG) is an important diagnostic tool in the practice of veterinary medicine. It is not only evaluates the electrical function of the heart, but ECG is also able to give information regarding non-cardiac illness. When performing ECGs, it is 
important to recognize the limitations as well as the benefits of their uses in clinical practice. Dehydration is seen in clinical condition like gastroenteritis, diarrhea, vomition etc. (Chakrabarti, 1994). Severity of dehydration can be conveniently diagnosed by haematobiochemical analysis but these are time consuming. Electrocardiography may be taken as a tool for the easy and quick diagnosis of the case of dehydration and electrolyte imbalance for their early treatment without losing valuable time to save the life of ailing animals (Hammer, 1978 and Dhanapalanet al., 1993). An ECG should be evaluated to diagnose dysrhythmias associated with hyperkalemia requiring immediate treatment. There is no set potassium level that predicts a dysrhythmia. ECG changes associated with hyperkalemia include tall T-waves, prolonged P-R interval, bradycardia, sino-ventricular rhythm, sine wave and asystole (Ettinger et al., 1974). In experimental settings, hyperkalemia has been associated with a defined series of ECG abnormalities, including shortening of QT interval, peaking of T waves, QRS prolongation, shortening of $\mathrm{PR}$ interval, reduction in amplitude of the $\mathrm{P}$ wave, loss of sinoatrial conduction with onset of a wide-complex 'sine-wave' ventricular rhythm, and ultimately asystole (Ettinger et al., 1974). Although no uniform threshold has been documented in animal models, the most severe cardiac manifestations have been shown to occur with serum potassium concentrations $>9 \mathrm{mEq} / \mathrm{L}$. Hence the study was conducted to know the ECG pattern in extra-cardiac diseases and its correlation with haemato-biochemical alterations.

\section{Materials and Methods}

The present study was carried out at Teaching Veterinary Clinical Complex (TVCC) and Division of Veterinary Medicine, Faculty of Veterinary Sciences and Animal Husbandry, Sher-e-Kashmir University of Agricultural Sciences and Technology,R.S.Pura, Jammu

\section{Selection of animals}

The dogs were selected on the basis of having principal complain of diarrhea and vomition for GE patients and having complained of polyuria, anuria, dysuria, anemia, halitosis and increase BUN and Creatinine level above $25 \mathrm{mg} / \mathrm{dl}$ and $1.5 \mathrm{mg} / \mathrm{dl}$, respectively were taken as UTD patients. The dogs brought to TVCC for routine checkup and having up to date vaccination and deworming status and normal clinico-physiological parameters were taken as healthy control. The animals were divided into three groups' viz. Gr.A(healthy $\operatorname{dogs}$ ), Gr.B (GE affected dogs) and Gr.C (UTD affected dogs) comprising six dogs in each group.

\section{Clinical Examination}

Under clinical examination, the conjunctiva, oral mucosa, heart rate, pulse, respiration and temperature were recorded. A detailed auscultation of all the four quarters was done. The size and shape of chest and abdominal cavity were also determined.

\section{Application of ECG}

A 12 lead standard ECG recorder, BPL CARDIART-6208 machine under all standard prescribed conditions was used in present study. The electrocardiograph has been standardized $1 \mathrm{~cm}=1 \mathrm{mV}$ so that each small box on the vertical axis equals $0.1 \mathrm{mV}$. The tracings were recorded at a paper speed of $50 \mathrm{~mm}$ per second so each small box on horizontal axis equals 0.02 seconds. The details of lead- II were included in this study. Electrocardiogram was then analyzed for the presence of ECG abnormality, if any.

The ECG was recorded with dog in standard body position (Tilley, 1992) i.e. restrained in right lateral recumbency on a wooden table with legs positioned parallel to each other and 
perpendicular to the long axis of body, and keeping the head and neck flat. The skin and electrodes were moistened with gel. The owner's presence at the end of the table was ensured in all cases to keep the dog calm and comfortable. No pharmacological preparation was used for restrain prior to ECG examination.

The front leg leads or electrodes (RA and LA) were attached to the appropriate forelegs just above the elbow. The rear leg leads (RL and LL) are likewise attached to the appropriate rear leg immediately proximal (above) to stifle (knee).

\section{Analysis of ECG Parameters}

The ECG parameters viz. $\mathrm{P}$ wave, QRS complex, T wave amplitude and duration, PR interval, QT interval and ST segment were recorded in each case.

\section{Collection of blood samples}

Eight $\mathrm{ml}$ of blood samples from each dog were collected from cephalic vein/saphenous vein. Two ml of blood was transferred to a EDTA vial for haematology estimation and $6 \mathrm{ml}$ blood was transferred to clot activator vial and serum was separated and kept in $-20 \mathrm{c}$ for future study.

\section{Haematological parameters}

Haematological parameters viz. $\mathrm{Hb}, \mathrm{PCV}$, TEC, MCV, MCH, MCHC, RDW, TLC and DLC (Neutrophil and lymphocyte) were determined as per the standard procedure (Jain et al., (1986).

\section{Biochemical parameters}

The serum biochemical parameters viz. Total Protein, Albumin, Globulin, Albumin:Globulin (A:G ratio), Creatinine, Blood Urea Nitrogen (BUN), Asparatate transaminase (AST), Alanine transaminase (ALT), Alkaline phosphatase (ALP), Total bilirubin, Indirect bilirubin, Calcium, Phosphorus, Sodium, Potassium and Chloride were analysed by automated biochemical analyzer (Chem-7, ERBA Company Ltd.) with the help of commercial kits (ERBA company Ltd).

\section{Statistical Analysis}

Data generated in the study was analyzed by IBM-SPSS 20 software. For comparison of different haemato-biochemical \& ECG parameters of healthy, GE and UTD were analysed by Independent T-test. The ECG changes were correlated with haematobiochemical alterations in the same dog using Pearson's correlation test.

\section{Results and Discussion}

\section{Electrocardiography studies}

The results of ECG of Gr.B andGr.Caffected dogs are shown in Table 1 and Figure 1, 2, 3, $4,5 \& 6$. Present study revealed that $\mathrm{Pa}(0.15 \pm$ $0.12 \mathrm{mv}$ and $0.13 \pm 0.10 \mathrm{mv})$, QRSa $(1.68 \pm$ $0.24 \mathrm{mv}$ and $0.78 \pm 0.11 \mathrm{mv})$ and $\mathrm{Td}(0.04 \pm$ $0.02 \mathrm{sec}$ and $0.04 \pm 0.01 \mathrm{sec}$ ) in Gr.B and Gr.C respectively were significantly $(\mathrm{P}<0.05)$ decreased as compared to Gr.A dogs (Table $1)$. The Ta value $(0.18 \pm 0.04 \mathrm{mv})$ of $\mathrm{Gr}$. $\mathrm{C}$ was also significantly decreased as compared to Gr.A. The rest ECG parameters did not show any significant alteration in both the groups as compared to health dogs. These findings particularly are in agreement with previous workers (Della et al., 1999; Mohan et al., 1994; Dhanapalan et al., 1993; Kline et al., 1992) who studied the effect of acute haemorrhage and urinary tract diseases on QRS amplitude in the lead II canine electrocardiogram. The decreased level of ECG parameters in Gr. B might be due to dehydration haemodilution and anaemia which caused decreased myocardial oxygenation, as 
a result myocardial hypoxia developed. In case of Gr. C, decreased in $\mathrm{Pa}$, Ta and $\mathrm{Td}$ might be due to increase serum potassium causes reduction in resting membrane potential and quicken depolarization reported by Dhanapalan et al., (1993), Kline et al., (1992) and Bernard et al., (1974).

\section{Alteration of Haemogram}

There was significant $(\mathrm{P}<0.05)$ decrease in $\mathrm{Hb}, \mathrm{PCV}, \mathrm{TEC}$ and MCHC in both Gr.B and Gr. C when compared to Gr. A (Table 2; Fig. 7 and 8). But there was significant $(\mathrm{P}<0.05)$ increase in $\mathrm{MCV}$ in both Gr.B and Gr.C dogs as compared to healthy dogs in present study (Table 2). There was no significant difference of the other haematological parameters among the three groups (Table 2). Decreased levels of hemoglobin, total erythrocyte count and packed cell volume were also noticed by Dharmadheeran et al., (2003), Biswas et al., (2005), Lee et al., (2012) and Ali et al.,(2014), Observed decrease HB, PCV, TEC and $\mathrm{MCHC}$ in Gr.B might be due to anaemia in haemorrhagic gastroenteritis (Mohan et al., 1994), dehydration (Rai et al., 1994) and mechanical obstruction and massive sloughing of intestinal epithelial cells (Mallela et al., 2006).

Table.1 Electrocardiogram of Healthy, Gastroenteritis and Urinary Tract disease affected dogs Mean \pm SE

\begin{tabular}{|l|l|l|l|}
\hline ECG Parameters & \multicolumn{3}{|c|}{ Group } \\
\cline { 2 - 4 } & \multicolumn{1}{|c|}{ Gr. A (n=6) } & \multicolumn{1}{|c|}{ Gr.B(n=6) } & \multicolumn{1}{|c|}{ Gr. C(n=6) } \\
\hline Pa $(\mathbf{m V})$ & $0.31 \pm 0.09$ & $0.15 \pm 0.12^{*}$ & $0.13 \pm 0.10^{*}$ \\
\hline Pd (sec.) & $0.03 \pm 0.13$ & $0.03 \pm 0.02$ & $0.02 \pm 0.01$ \\
\hline QRSa (mV) & $2.50 \pm 0.21$ & $1.68 \pm 0.24^{*}$ & $0.78 \pm 0.11^{*}$ \\
\hline QRSd (sec.) & $0.05 \pm 0.00$ & $0.04 \pm 0.02$ & $0.05 \pm 0.10$ \\
\hline Ta (mV) & $0.35 \pm 0.15$ & $0.24 \pm 0.12$ & $0.18 \pm 0.04^{*}$ \\
\hline Td (sec.) & $0.23 \pm 0.81$ & $0.04 \pm 0.02^{*}$ & $0.04 \pm 0.01^{*}$ \\
\hline STs (sec.) & $0.15 \pm 0.05$ & $0.14 \pm 0.02$ & $0.13 \pm 0.03$ \\
\hline QTi (sec.) & $0.17 \pm 0.02$ & $0.16 \pm 0.02$ & $0.17 \pm 0.03$ \\
\hline PRi (sec.) & $0.07 \pm 0.01$ & $0.09 \pm 0.05$ & $0.07 \pm 0.05$ \\
\hline
\end{tabular}

$* \mathrm{P} \leq 0.05$,Gr.A=healthy, Gr.B=Gastroenteritis, Gr. C.=Urinary Tract Disease

Table.2 Haematologial parameters of healthy, gastroenteritis disease and urinary tract diseases in dogs

\begin{tabular}{|c|c|c|c|}
\hline & & & ean \pm SE \\
\hline \multirow[t]{2}{*}{ Parameters } & \multicolumn{3}{|c|}{ Group } \\
\hline & Gr.A (n=6) & Gr.B $(n=6)$ & Gr.C $(n=6)$ \\
\hline $\mathrm{Hb}(\mathrm{g} / \mathrm{dl})$ & $15.28 \pm 1.35$ & $11.7 \pm 1.71 *$ & $6.56 \pm 1.24 *$ \\
\hline $\operatorname{PCV}(\%)$ & $44.53 \pm 2.30$ & $34.0 \pm 6.94^{*}$ & $34.0 \pm 2.44^{*}$ \\
\hline TEC $(\times 106 / \mu \mathrm{l})$ & $6.96 \pm 0.48$ & $4.29 \pm 0.34^{*}$ & $1.38 \pm 0.80^{*}$ \\
\hline $\operatorname{MCV}(\mathbf{f L})$ & $65.71 \pm 6.83$ & $78.71 \pm 8.84^{*}$ & $93.86 \pm 0.87 *$ \\
\hline MCH (pg) & $22.07 \pm 2.97$ & $21.3 \pm 1.99$ & $25.44 \pm 0.94$ \\
\hline MCHC (g/dl) & $33.58 \pm 2.80$ & $27.65 \pm 2.20^{*}$ & $27.08 \pm 0.34 *$ \\
\hline RDW (\%) & $12.69 \pm 0.48$ & $13.1 \pm 1.47$ & $12.69 \pm 0.48$ \\
\hline TLC $(x 103 / \mu \mathrm{l})$ & $11.88 \pm 0.84$ & $12.1 \pm 1.55$ & $10.51 \pm 1.58$ \\
\hline Neutrophils (\%) & $72.58 \pm 2.73$ & $74.27 \pm 2.38$ & $71.48 \pm 2.30$ \\
\hline Lymphocytes (\%) & $18.68 \pm 3.33$ & $18.68 \pm 3.33$ & $21.6 \pm 1.00$ \\
\hline
\end{tabular}

$* \mathrm{P} \leq 0.05$ 
Table.3 Serum biochemical profile of Healthy, gastroenteritis disease and urinary tract diseases affected dogs

Mean \pm SE

\begin{tabular}{|c|c|c|c|}
\hline \multirow{2}{*}{ Parameters } & \multirow[b]{2}{*}{ Gr.A $(n=6)$} & \multirow[b]{2}{*}{ Gr.B $(n=6)$} & \multirow[b]{2}{*}{ Gr.C $(n=6)$} \\
\hline & & & \\
\hline AST (IU/L) & $58.28 \pm 3.97$ & $76.33 \pm 5.46^{*}$ & $110.83 \pm 4.91 *$ \\
\hline ALT (IU/L) & $31.96 \pm 6.07$ & $23.22 \pm 5.21$ & $95.5 \pm 3.87 *$ \\
\hline ALP (IU/L) & $92.35 \pm 6.85$ & $114.44 \pm 8.20 *$ & $133.83 \pm 5.55^{*}$ \\
\hline TB (mg/dl) & $0.30 \pm 0.17$ & $0.23 \pm 0.13$ & $1.52 \pm 0.12$ \\
\hline IB (mg/dl) & $0.10 \pm 0.08$ & $0.18 \pm 0.12$ & $0.74 \pm 0.50$ \\
\hline TP (g/L) & $6.73 \pm 0.19$ & $5.63 \pm 0.70$ & $6.34 \pm 0.24$ \\
\hline Albumin (g/L) & $3.55 \pm 0.40$ & $2.18 \pm 0.53 *$ & $4.89 \pm 0.09$ \\
\hline AG Ratio & $1.13 \pm 0.24$ & $0.66 \pm 0.22$ & $0.29 \pm 0.05$ \\
\hline BUN (mg/dl) & $14.26 \pm 5.13$ & $19.49 \pm 5.02$ & $188.5 \pm 7.61^{*}$ \\
\hline $\begin{array}{l}\text { Creatinine } \\
\text { (mg/dl) }\end{array}$ & $0.83 \pm 0.36$ & $1.06 \pm 0.47$ & $6.81 \pm 1.92 *$ \\
\hline Ca (mg/dl) & $8.76 \pm 0.89$ & $9.18 \pm 1.31$ & $9.34 \pm 0.89$ \\
\hline$P(\mathrm{mg} / \mathrm{dl})$ & $4.38 \pm 0.35$ & $5.42 \pm 2.38$ & $8.62 \pm 2.56^{*}$ \\
\hline $\mathrm{Na}(\mathrm{mEq} / \mathrm{L})$ & $143.66 \pm 9.13$ & $141.68 \pm 8.60$ & $127.16 \pm 9.27$ \\
\hline $\mathrm{K}(\mathrm{mEq} / \mathbf{L})$ & $4.53 \pm 0.53$ & $3.37 \pm 1.20$ & $6.08 \pm 0.58$ \\
\hline Cl (mEq/L) & $117.5 \pm 5.52$ & $102.11 \pm 6.35$ & $109.66 \pm 5.08$ \\
\hline
\end{tabular}

$* \mathrm{P} \leq 0.05$

Table.4 Correlation between ECG and haemogram of gastroenteritis disease affected dogs

\begin{tabular}{|l|l|l|l|l|l|l|l|l|l|}
\hline Parameters & Pa & Pd & QRSa & QRSd & Ta & Td & STs & QTi & PRi \\
\hline Hb & -0.11 & -0.06 & 0.34 & 0.12 & 0.52 & 0.10 & 0.50 & 0.14 & 0.34 \\
\hline PCV & 0.15 & 0.46 & $0.75^{*}$ & -0.11 & 0.39 & 0.05 & 0.22 & 0.48 & 0.44 \\
\hline TEC & 0.30 & 0.22 & 0.41 & 0.03 & 0.21 & -0.10 & 0.09 & 0.17 & 0.31 \\
\hline MCV & 0.20 & 0.40 & 0.42 & 0.22 & 0.13 & -0.16 & 0.39 & 0.16 & 0.16 \\
\hline MCH & 0.57 & $0.70^{*}$ & 0.46 & -0.11 & -0.34 & -0.55 & 0.07 & 0.09 & 0.45 \\
\hline MCHC & -0.00 & -0.16 & -0.18 & -0.30 & -0.20 & -0.12 & -0.52 & 0.04 & -0.02 \\
\hline RDW & -0.00 & -0.11 & -0.28 & -0.03 & -0.11 & -0.03 & -0.13 & 0.23 & -0.09 \\
\hline TLC & 0.08 & 0.33 & 0.51 & 0.11 & 0.38 & -0.04 & 0.53 & 0.25 & 0.25 \\
\hline Neutrophil & 0.17 & 0.02 & 0.46 & -0.03 & -0.47 & -0.33 & -0.21 & -0.46 & -0.33 \\
\hline Lymphocyte & 0.12 & 0.23 & 0.35 & 0.12 & 0.27 & 0.08 & 0.11 & -0.67 & 0.49 \\
\hline
\end{tabular}

$* \mathrm{P} \leq 0.05$ 
Table.5 Correlation between ECG and biochemical of gastroenteritis disease affected dogs

\begin{tabular}{|l|l|l|l|l|l|l|l|l|l|}
\hline Parameters & Pa & Pd & QRSa & QRSd & Ta & Td & STs & QTi & PRi \\
\hline AST & 0.38 & 0.63 & $0.68^{*}$ & 0.06 & 0.13 & -0.20 & 0.31 & 0.56 & 0.57 \\
\hline ALT & 0.30 & 0.57 & 0.63 & 0.07 & 0.20 & -0.11 & 0.36 & 0.62 & 0.48 \\
\hline ALP & -0.22 & -0.34 & -0.56 & 0.04 & -0.30 & 0.06 & -0.21 & $-0.67^{*}$ & $-0.80^{* *}$ \\
\hline TB & 0.21 & 0.43 & 0.67 & -0.08 & 0.42 & -0.00 & 0.35 & 0.78 & 0.79 \\
\hline IB & 0.33 & 0.60 & 0.67 & -0.11 & 0.30 & -0.10 & 0.41 & 0.82 & 0.79 \\
\hline Albumin & 0.17 & 0.31 & 0.08 & 0.03 & -0.25 & -0.12 & 0.01 & -0.05 & -0.24 \\
\hline Globulin & 0.37 & 0.51 & 0.69 & 0.01 & 0.21 & -0.18 & 0.18 & $0.69^{*}$ & $0.82^{* *}$ \\
\hline AG ratio & -0.10 & -0.11 & -0.37 & 0.02 & -0.32 & -0.10 & -0.44 & -0.67 & -0.22 \\
\hline BUN & 0.48 & 0.38 & -0.19 & 0.41 & -0.07 & -0.07 & 0.48 & 0.49 & $0.87^{* *}$ \\
\hline Creatinine & 0.14 & 0.23 & 0.35 & 0.12 & 0.27 & 0.08 & 0.11 & -0.67 & 0.49 \\
\hline Ca & 0.28 & 0.39 & -0.19 & 0.35 & -0.10 & -0.10 & 0.22 & -0.00 & 0.21 \\
\hline P & 0.21 & 0.40 & 0.13 & -0.08 & -0.16 & -0.22 & 0.06 & -0.04 & 0.69 \\
\hline Na & -0.42 & -0.06 & 0.39 & 0.08 & 0.08 & -0.08 & -0.55 & -0.53 & 0.65 \\
\hline K & -0.01 & 0.03 & -0.41 & -0.15 & 0.14 & -0.14 & 0.07 & -0.15 & -0.41 \\
\hline Cl & -0.08 & -0.43 & 0.08 & -0.27 & -0.02 & -0.04 & -0.26 & -0.07 & -0.70 \\
\hline
\end{tabular}

$* \mathrm{P} \leq 0.05 * * \mathrm{P} \leq 0.01$

Table.6 Correlation between ECG and haemogram of urinary tract disease affected dogs

\begin{tabular}{|l|l|l|l|l|l|l|l|l|l|}
\hline Parameters & Pa & Pd & QRSa & QRSd & Ta & Td & STs & QTi & PRi \\
\hline Hb & 0.01 & 0.45 & -0.09 & 0.15 & -0.32 & -0.21 & -0.44 & -0.58 & 0.32 \\
\hline PCV & -0.31 & 0.40 & -0.48 & 0.59 & -0.31 & -0.31 & -0.32 & -0.51 & 0.56 \\
\hline TEC & -0.08 & 0.45 & -0.39 & 0.22 & 0.46 & 0.46 & 0.22 & 0.04 & 0.54 \\
\hline MCV & 0.06 & 0.16 & 0.23 & 0.16 & -0.31 & -0.31 & 0.48 & 0.36 & -0.29 \\
\hline MCH & -0.36 & -0.25 & 0.49 & 0.34 & -0.35 & -0.35 & $0.86 *$ & 0.77 & -0.52 \\
\hline MCHC & -0.07 & 0.04 & 0.46 & 0.11 & -0.49 & -0.49 & 0.25 & 0.16 & -0.33 \\
\hline RDW & 0.27 & 0.13 & 0.21 & -0.66 & 0.38 & 0.38 & -0.69 & -0.61 & 0.26 \\
\hline TLC & 0.20 & -0.47 & 0.53 & -0.77 & 0.35 & 0.35 & -0.25 & -0.01 & -0.32 \\
\hline Neutrophil & 0.16 & -0.10 & 0.41 & -0.223 & 0.13 & 0.13 & 0.56 & 0.57 & -0.422 \\
\hline Lymphocyte & -0.21 & -0.73 & 0.86 & -0.46 & 0.17 & 0.89 & 0.36 & 0.54 & -0.60 \\
\hline
\end{tabular}

$* \mathrm{P} \leq 0.05$ 


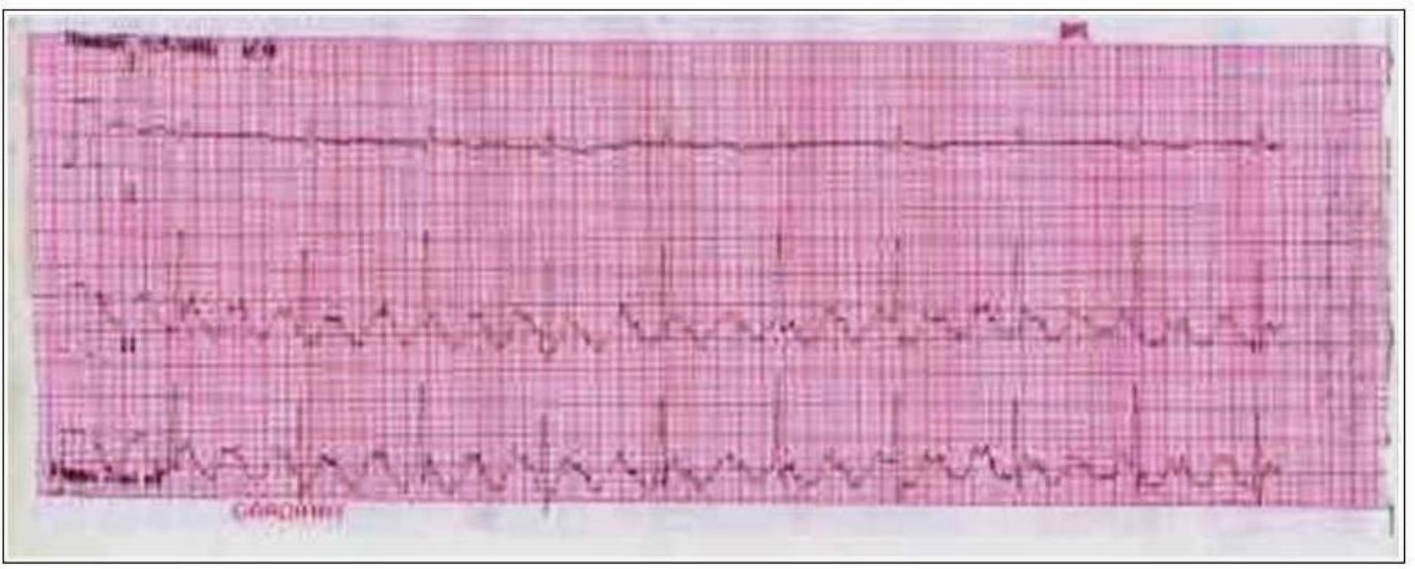

Fig: 1. ECG of 3 year old, male GSD dogs suffering from GE. Decrease in Pa and QRSs clearly visible.

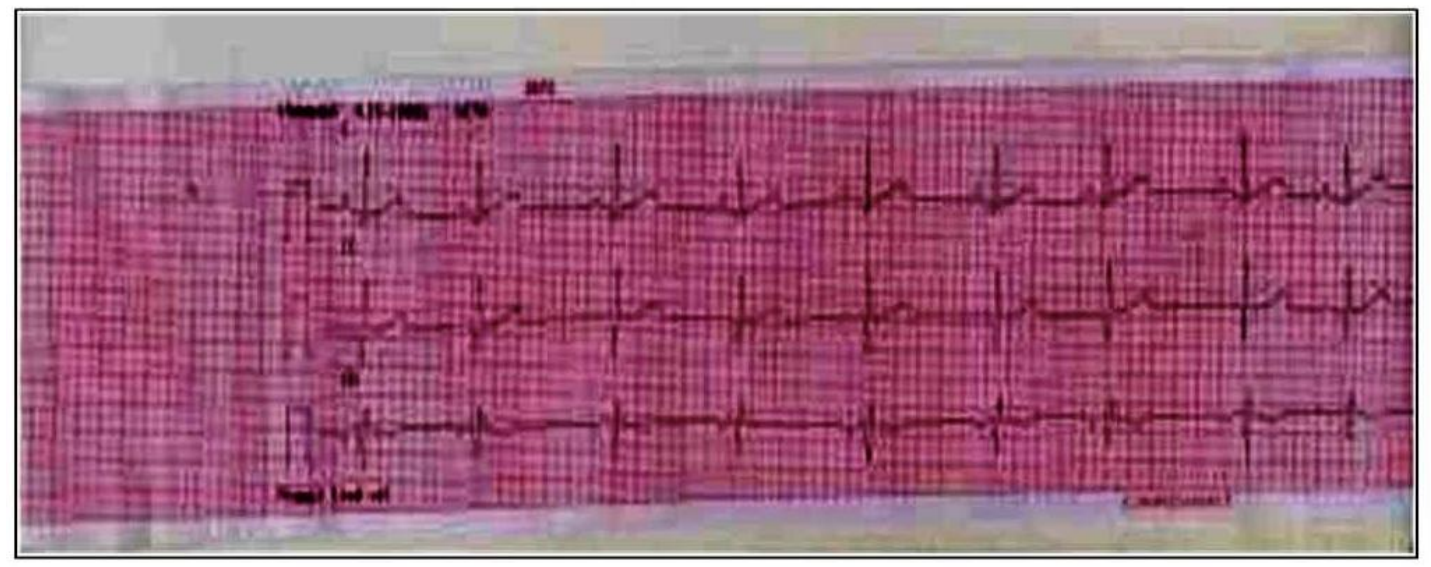

Fig. 2. ECG of 18 month old male Labrador dogs suffering from HGE, almost absence of $P$ wave or significant decrease in $\mathrm{Pa}, \mathrm{QRSa}$ and $\mathrm{Ta}$ is noticeable

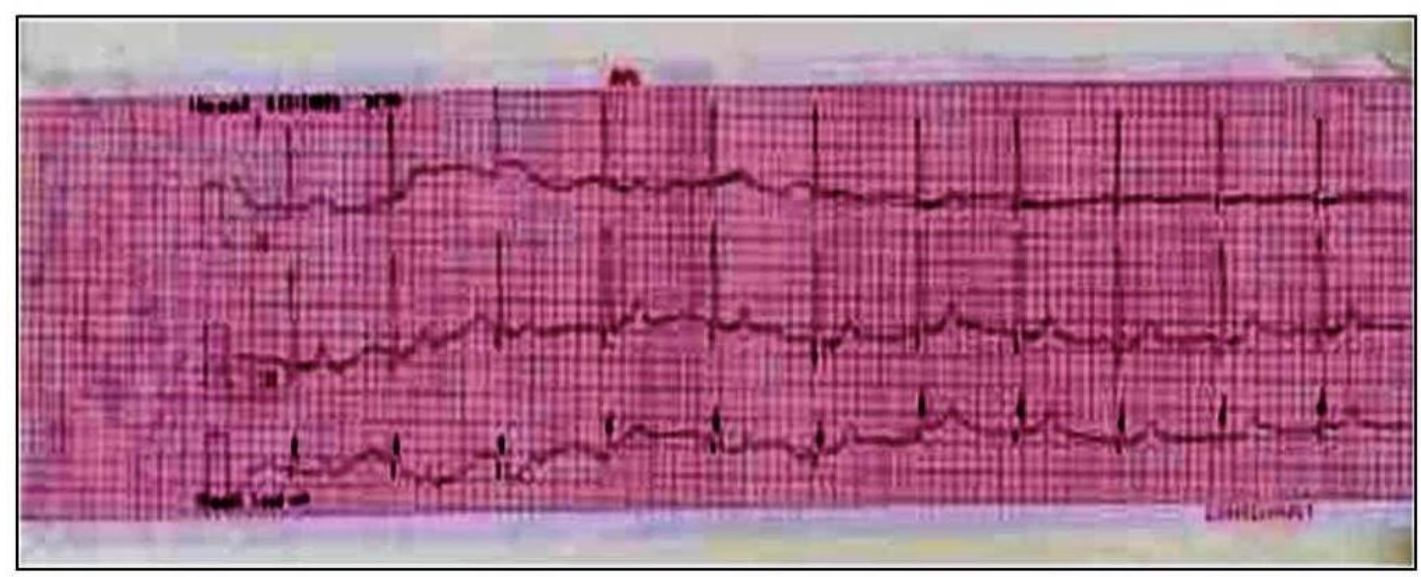

Fig.3.: ECG of 02 year old female GSD with CPV infection. Absences or decrease in $\mathrm{Pa}, \mathrm{R}$ alternce and decrease in $\mathrm{Ta}$ is visible 


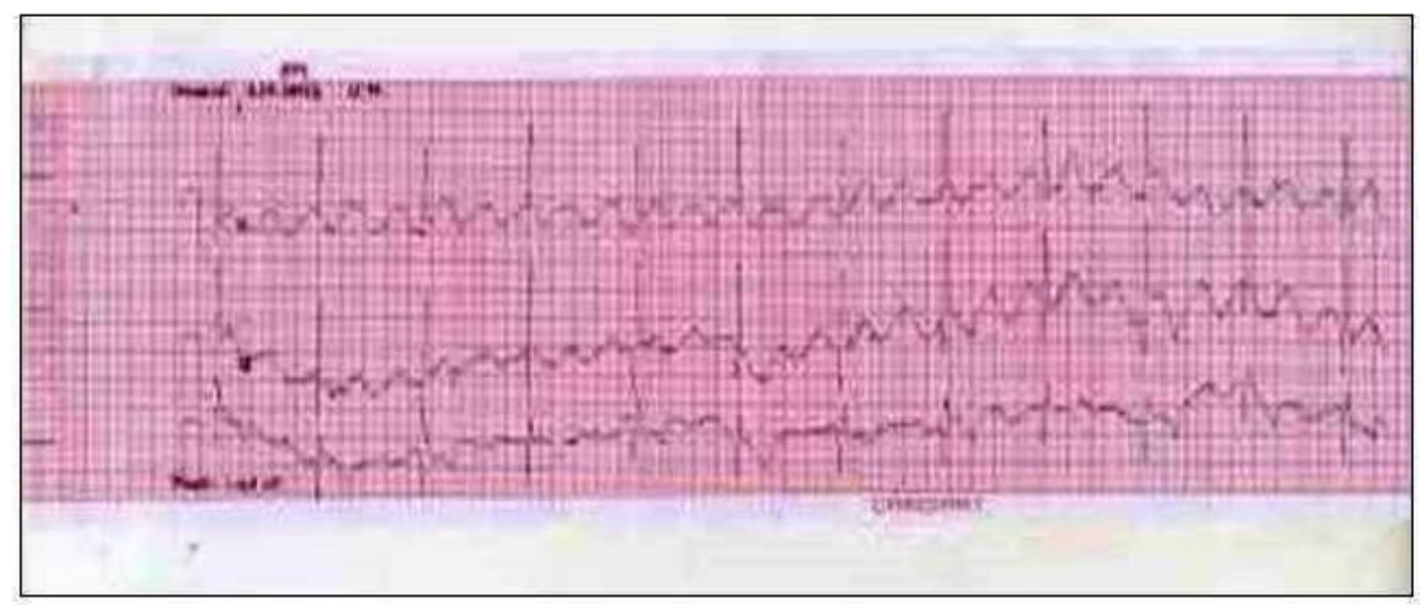

Fif.4. ECG of 6 year old male GSD suffering from CKD. Decrease in $P a, Q R S$ a and $\mathrm{Ta}$ along with increase in $\mathrm{Td}$ is noticeable

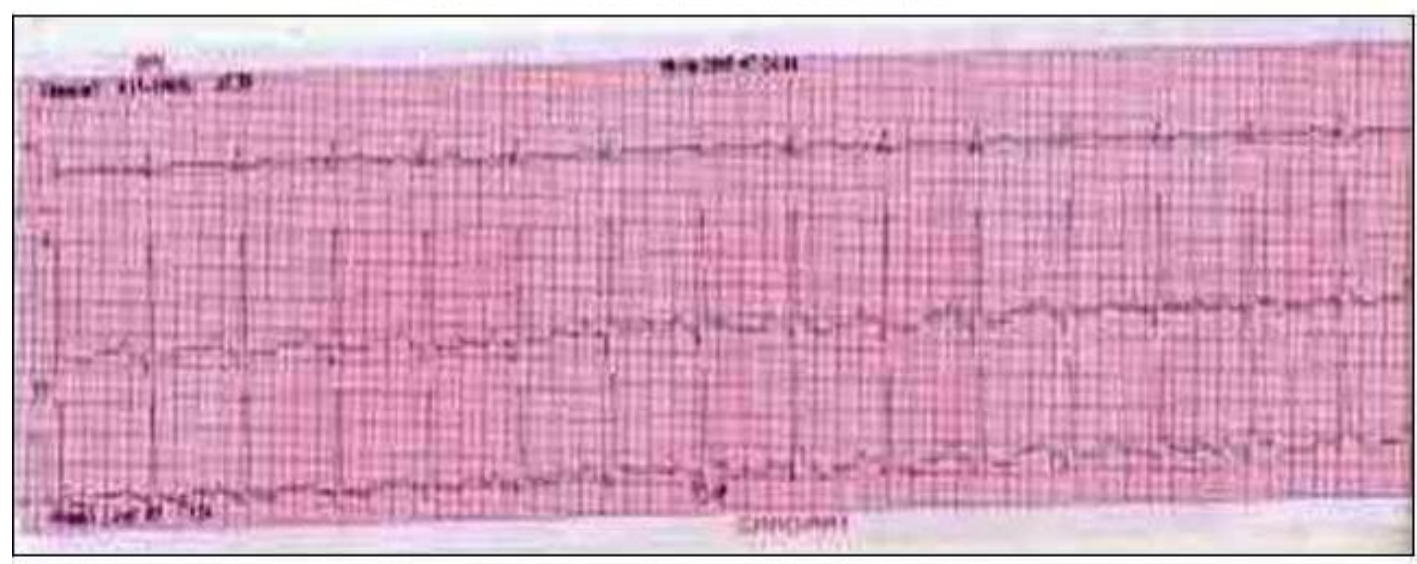

Fig.5. ECG of 4 year old male spitz suffering from ARI. Decrease in $\mathrm{Pa}, \mathrm{QRSa}, \mathrm{Ta}$ and $T d$ is visible

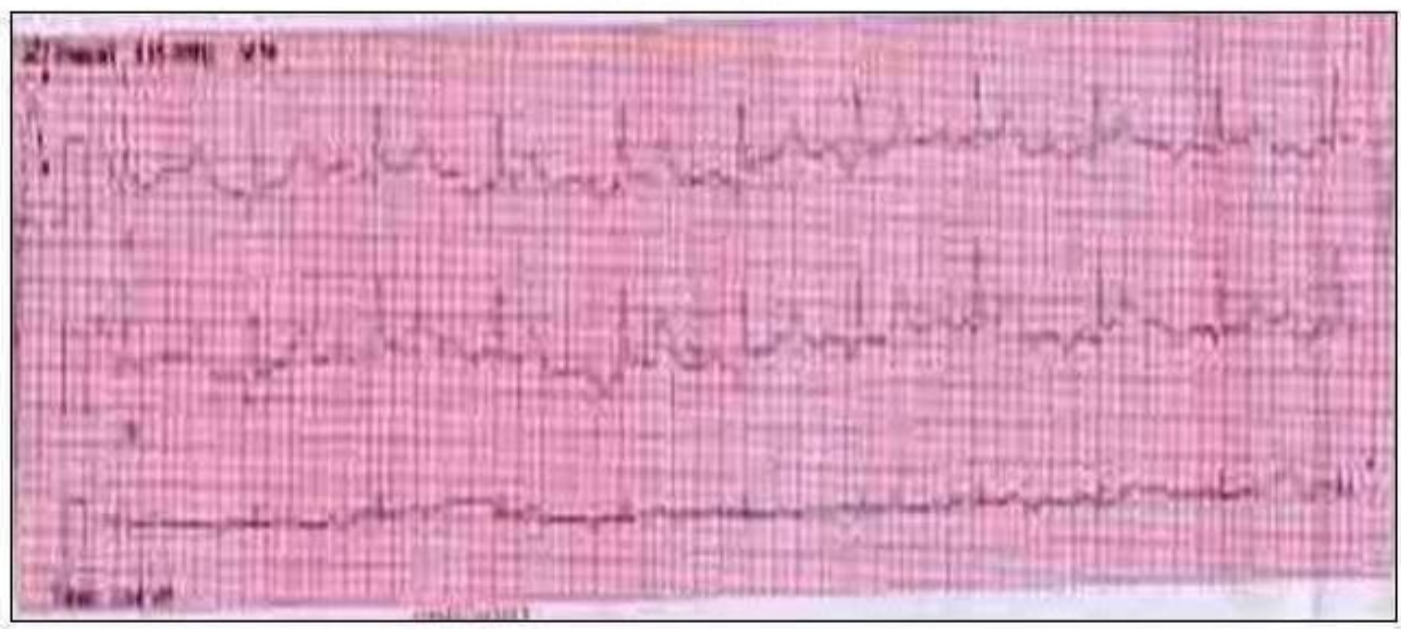

Fig.6. : ECG of 6 year old female GSD suffering from CKD. Decrease in $\mathrm{Pa}, \mathrm{QRSa}$ and $\mathrm{Td}$ along with increase in $\mathrm{Ta}$ is appreciable. 
Fig.7 Haematologial parameters of healthy, gastroenteritis disease and urinary tract diseases in $\operatorname{dog} \mathrm{s}$

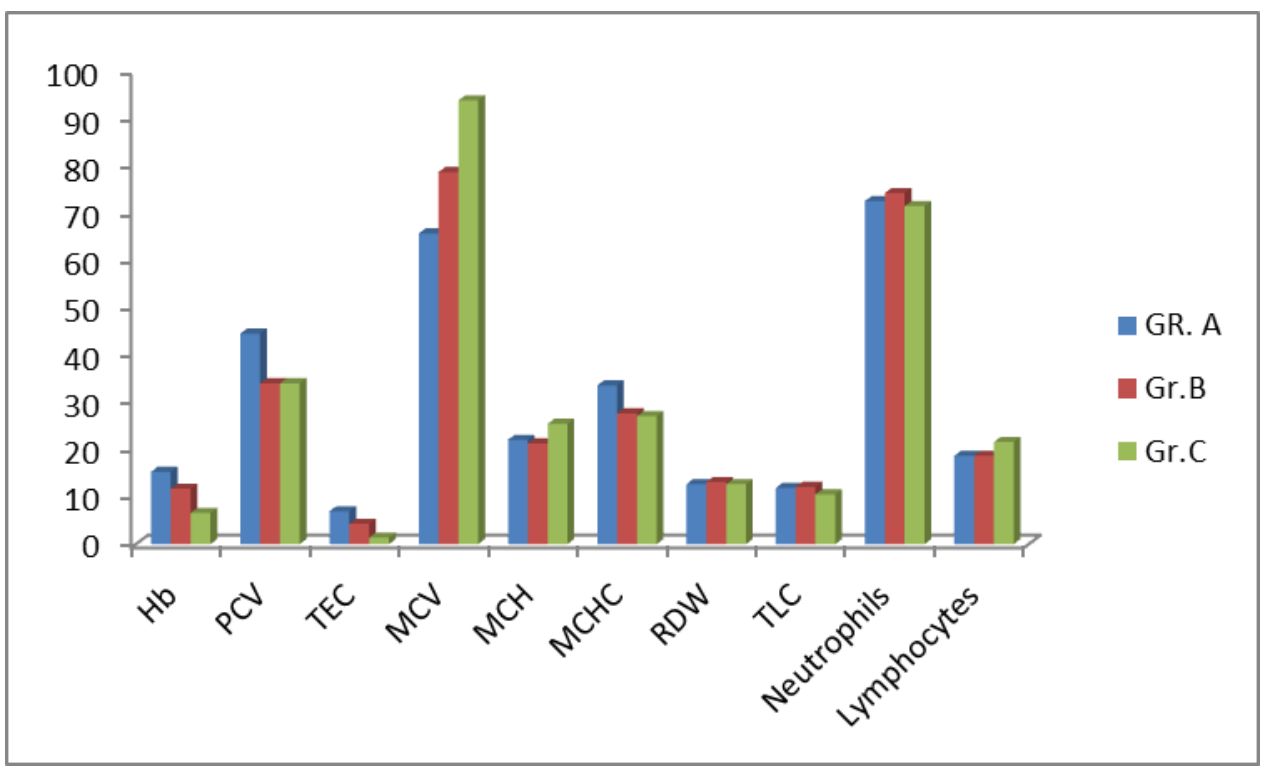

Fig.8 Serum biochemical profile of Healthy, gastroenteritis disease and urinary tract diseases affected dogs

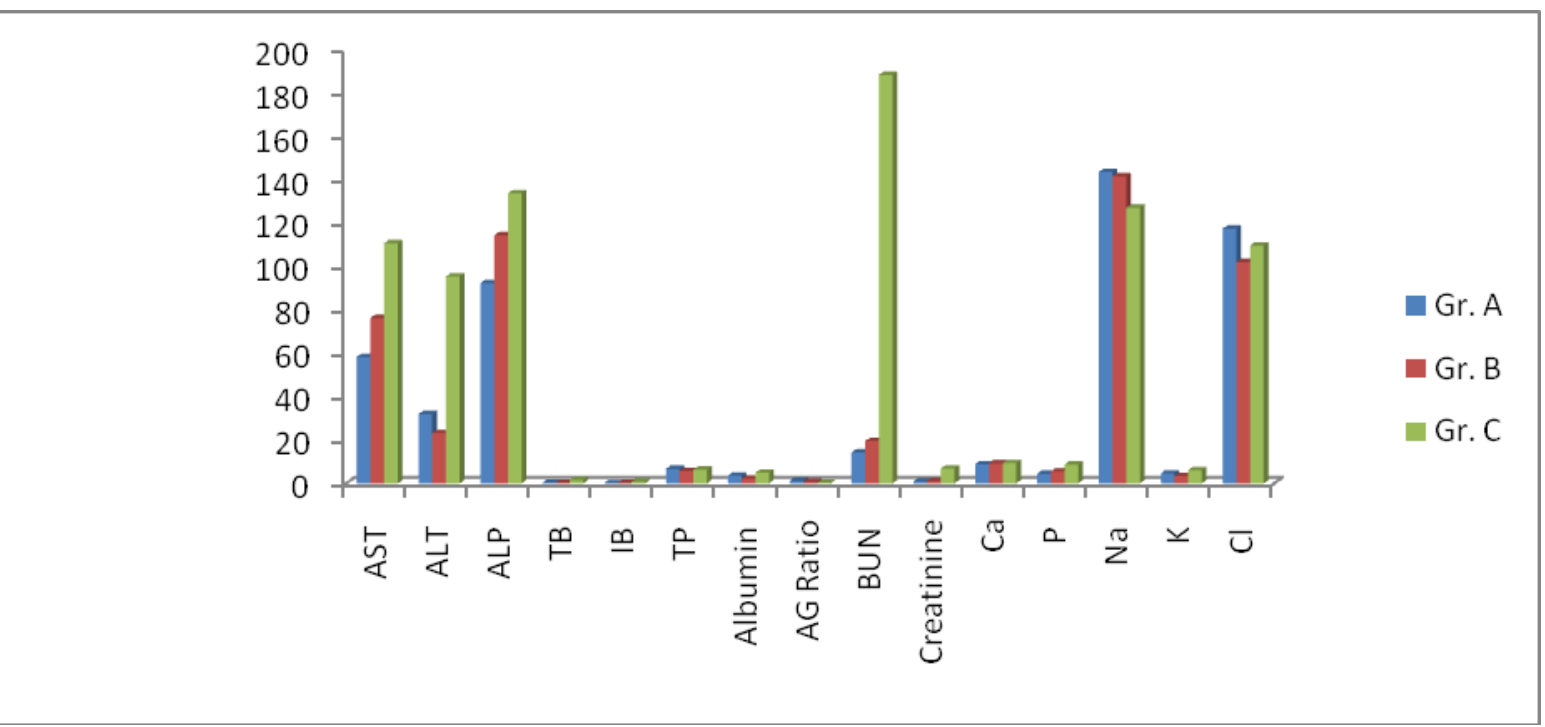


Fig.9 Correlation between ECG and haemogram of gastroenteritis disease affected dogs

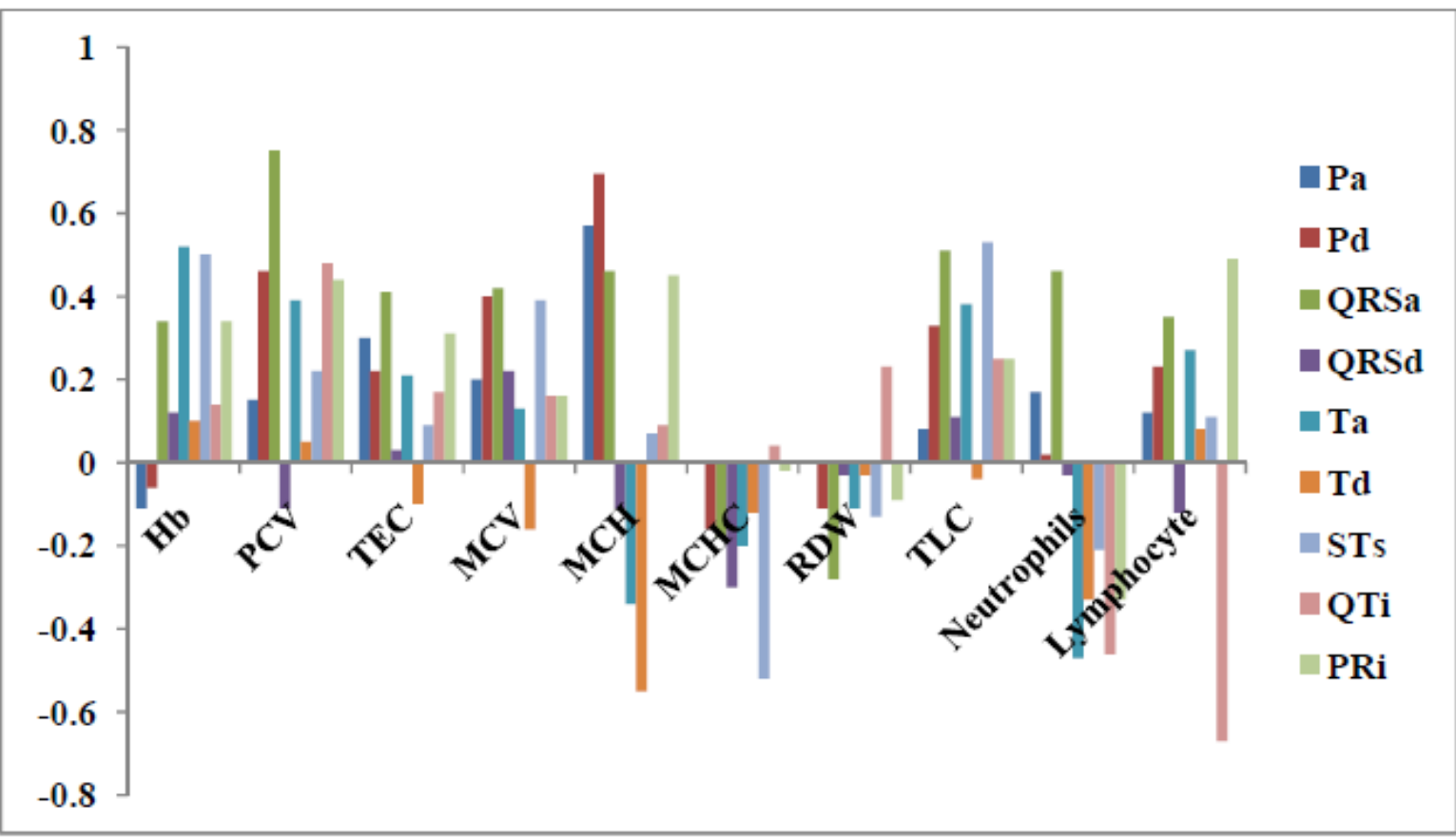

Fig.10 Correlation between ECG and biochemical of gastroenteritis disease affected dogs

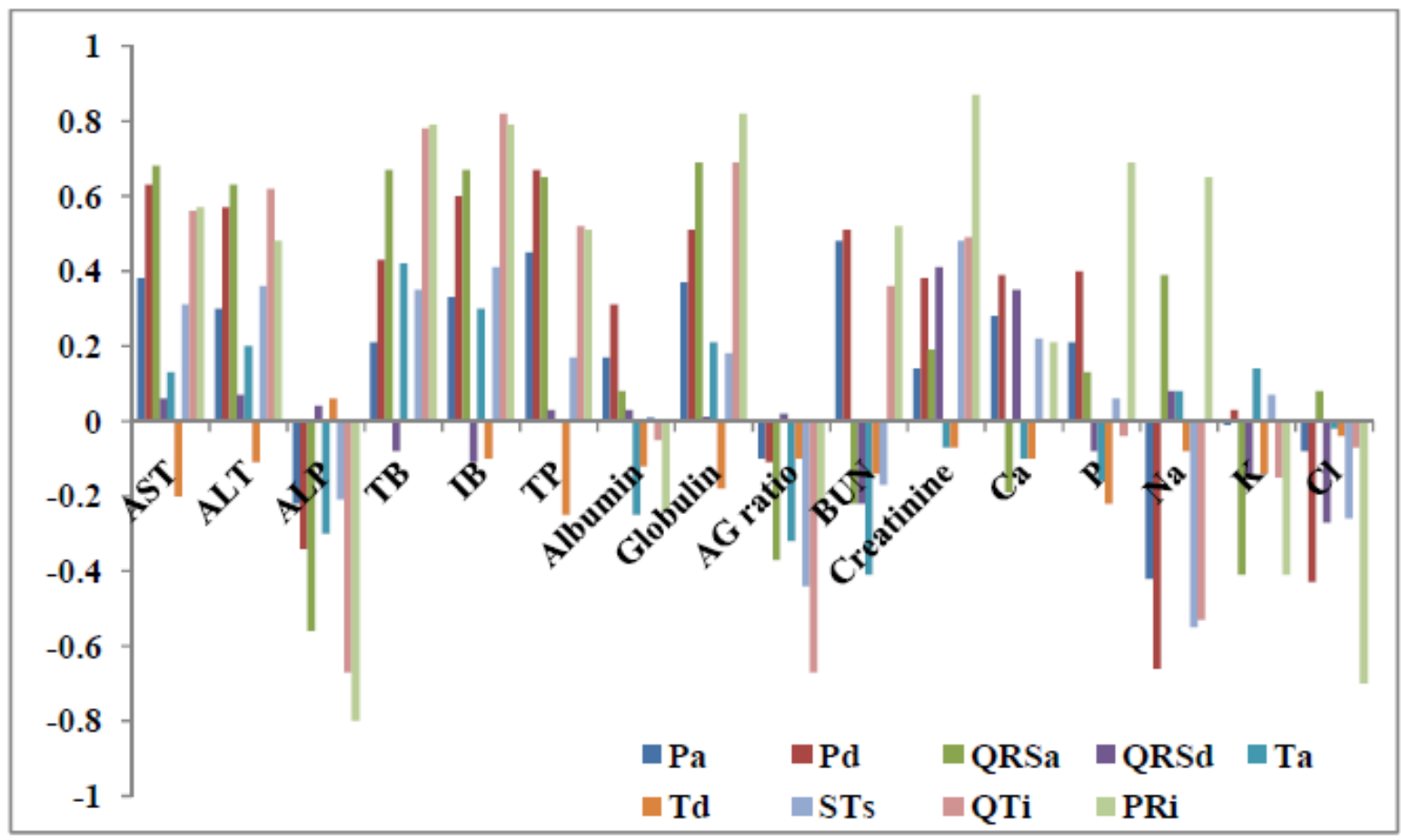


Fig.11 Correlation between ECG and haemogram of urinary tract disease affected dogs

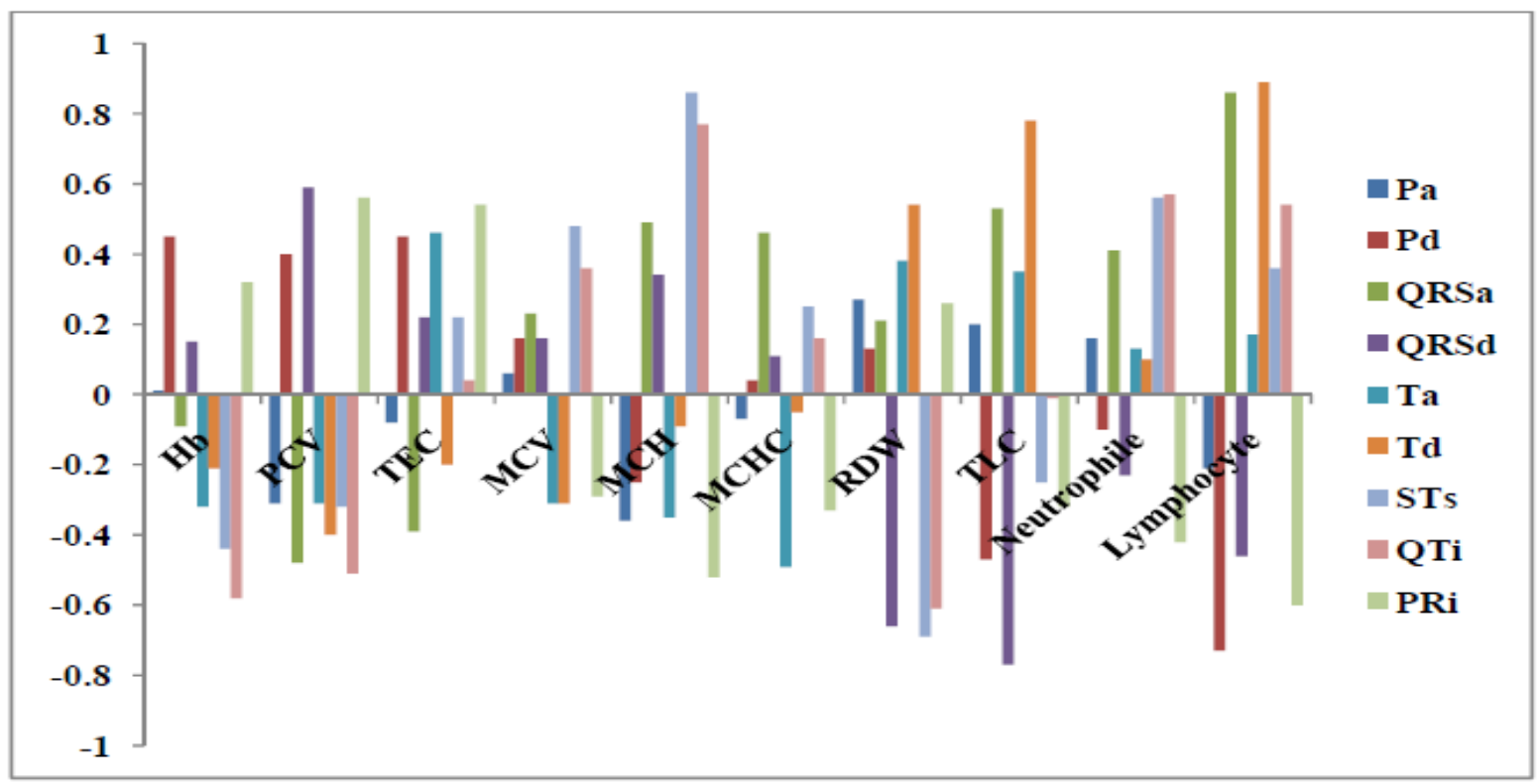

Fig.12 Correlation between ECG and biochemical of urinary tract diseases affected dogs

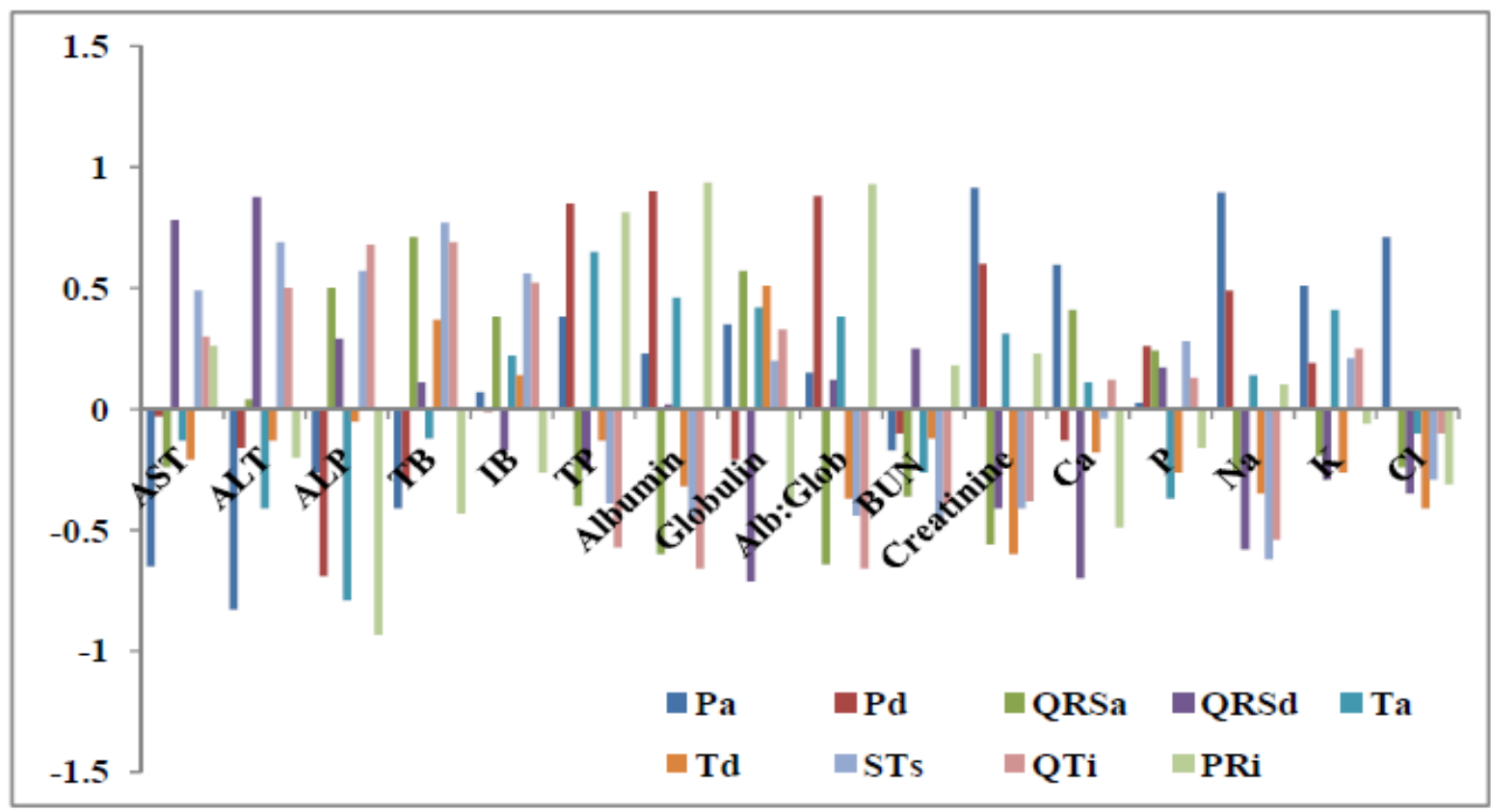

In case of Gr.C, decreased level of haematological parameters might be depressed renal erythropoietin factor production from impaired kidney. Blood loss in the form of hematemesis or malena and decreased RBCs survival due to impaired kidney function
(Dharmadheeranet al., 2003, Biswas et al., 2005, Baruah et al., 2005).Increase in MCV might be due to macrocytic normochromic type of anemia found in chronic renal failure and sort of liver involvement (Mallela et al., 2006). 
Table. 7 Correlation between ECG and biochemical of urinary tract diseases affected dogs

\begin{tabular}{|l|l|l|l|l|l|l|l|l|l|}
\hline Parameters & Pa & Pd & QRSa & QRSd & Ta & Td & STs & QTi & PRi \\
\hline AST & -0.65 & -0.03 & -0.24 & 0.78 & -0.13 & -0.21 & 0.49 & 0.30 & 0.26 \\
\hline ALT & -0.828 & -0.16 & 0.04 & 0.878 & -0.41 & -0.13 & 0.69 & 0.50 & -0.20 \\
\hline ALP & -0.26 & -0.69 & 0.50 & 0.29 & -0.79 & -0.05 & 0.57 & 0.68 & $-0.931^{* *}$ \\
\hline TB & -0.41 & -0.30 & 0.71 & 0.11 & -0.12 & 0.37 & 0.77 & 0.69 & -0.43 \\
\hline IB & 0.07 & -0.01 & 0.38 & -0.17 & 0.22 & 0.14 & 0.56 & 0.52 & -0.26 \\
\hline TP & 0.38 & $0.85^{*}$ & -0.40 & -0.25 & 0.65 & -0.133 & -0.39 & -0.57 & 0.814 \\
\hline Albumin & 0.23 & $0.90^{*}$ & -0.60 & 0.02 & 0.46 & -0.32 & -0.45 & -0.66 & $0.935^{* *}$ \\
\hline Globulin & 0.35 & -0.21 & 0.57 & -0.71 & 0.42 & 0.51 & 0.20 & 0.33 & -0.40 \\
\hline AG ratio & 0.15 & 0.88 & -0.64 & 0.12 & 0.38 & -0.37 & -0.44 & -0.66 & $0.93^{* *}$ \\
\hline BUN & -0.17 & -0.10 & -0.36 & 0.25 & -0.26 & -0.12 & -0.45 & -0.39 & 0.18 \\
\hline Creatinine & 0.915 & 0.60 & -0.56 & -0.41 & 0.31 & -0.60 & -0.41 & -0.38 & 0.233 \\
\hline Ca & 0.597 & -0.13 & 0.41 & -0.70 & 0.11 & -0.18 & -0.04 & 0.12 & -0.49 \\
\hline P & 0.025 & 0.26 & 0.24 & 0.17 & -0.37 & -0.26 & 0.28 & 0.13 & -0.16 \\
\hline Na & 0.0894 & 0.49 & -0.26 & -0.58 & 0.14 & -0.35 & -0.62 & -0.54 & 0.10 \\
\hline K & 0.51 & 0.19 & -0.19 & -0.29 & 0.41 & -0.26 & 0.21 & 0.25 & -0.06 \\
\hline Cl & 0.71 & 0.00 & -0.24 & -0.35 & -0.10 & -0.41 & -0.29 & -0.10 & -0.31 \\
\hline
\end{tabular}

$* \mathrm{P} \leq 0.05^{* *} \mathrm{P} \leq 0.01$

\section{Biochemical Analysis}

Biochemical analysis in present study (Table 3 and Fig. 8 and 9) revealed that there was significant $(\mathrm{P}<0.05)$ decrease of AST $(76.33 \pm$ $5.46 \mathrm{IU} / \mathrm{L}$ and $110.83 \pm 4.91 \mathrm{IU} / \mathrm{L})$, ALP $(114.44 \pm 8.20 \mathrm{IU} / \mathrm{L}$ and $133.83 \pm 5.55 \mathrm{IU} / \mathrm{L})$ in Gr.B and Gr.C respectively as compared to Gr.A ( AST-58.28 \pm 3.97IU/L and ALP-92.35 $\pm 6.85 \mathrm{IU} / \mathrm{L})$. But $\mathrm{ALT}(95.5 \pm 3.87 \mathrm{IU} / \mathrm{L})$, BUN $(188.5 \pm 7.61 \mathrm{mg} / \mathrm{dl})$, creatinine $(6.81 \pm$ $1.92 \mathrm{mg} / \mathrm{dl})$ and $\mathrm{P}(8.62 \pm 2.56 \mathrm{mg} / \mathrm{dl})$ in Gr. C were significantly $(\mathrm{P}<0.05)$ increase as compared to Gr. A and Gr. B (Table 3). The Albumin level in case of Gr.B (2.18 \pm $0.53 \mathrm{~g} / \mathrm{L})$ was significantly $(\mathrm{P}<0.05)$ decreased as compared to Gr. A and Gr.C (Table 3). The rest biochemical did not show any significant alteration as compared to healthy dogs. These observations were in corroboration with the findings of Dharmadheeran et al., (2005) and Shah et al., (2013).Decrease in Albumin and increase AST in gastroenteritis infected dogs might be due to involvement of liver and severe protein losing enteropathy due to intestinal villi damage or intestinal haemorrhage (Grigonis et al., 2002). Increase in ALP might be due to hepatic hypoxia secondary to severe hypovolemia or the absorption of toxic substances due to loss of the gut barrier (Shah et al., 2013).IncreasedBUN and serum creatinine concentration indicated the renal dysfunction. These values were elevated, when 70-75 per cent of thenephrons become non-functional. Loss of phosphorus homeostasis due to excretion failure in chronic kidney disease results in hyperphosphatemia (Craver et al., 2007).

\section{Correlation studies}

The correlation statistic between ECG and haematology of GE affected dogs revealed a positive correlation between $\mathrm{Pd}$ and $\mathrm{MCH}$ and QRSa and PCV (Table 4 and Fig. 9). 
Similarly positive correlation between Pd and TP, QRSa and AST, QTi and globulin and PRiwith Globulin and creatinine were recorded in this study (Table 5 and Fig. 10). But QTi and PRi were negatively correlated with ALP.

Similarly, correlation statistic between ECG and haematology of UTD affected dogs revealed a positive correlation between STs and $\mathrm{MCH}$. The study also revealed positive correlation of $\mathrm{Pd}$ with $\mathrm{TP}$ and albumin and QRSd with ALT and PRi with TP, Albumin and $A / G$ ratio (Table 6 and Fig.10). But there was negative correlation of PRi with ALP (Table 6 and 7; Fig.10-12).

These findings are in agreement with other workers who also reported about correlation between ECG and haemato-biochemical changes (Tatina et al., 2013; Tilley, 1992). Decrease HB, PCV and TEC lead to anaemia and as result myocardial hypoxia developed which showed increased $\mathrm{T}$ wave amplitude, $\mathrm{P}$ wave duration, QRS complex and QT interval (Tatina et al., 2013; Tilley, 1992; Scheet et al., 1985).

In the present study, it was concluded that the ECG parameters like $P$ wave duration, $T$ wave amplitude and QRS complex were altered in the extra-cardiac diseases of dogs viz. gastroenteritis and urinary tract diseases. There was a positive correlation between ECG and haemato-biochemical parameters in gastroenteritis and urinary tract diseases. These findings might be help for the better management of extra-cardiac diseases in dogs.

\section{Acknowledgment}

The help rendered by Miss Radhika Thakur (Ph.D. Scholar, Statistics), College of Forestry, Department of Basic Sciences, Dr. Yashwant Singh Parmar University of Horticulture and Forestry, Nauni, Solan
(Himachal Pradesh) for statistical analysis in the present study is duly acknowledged.

\section{References}

Baruah MS, Hazarika GC and Chakravarty P, Haematological profile in canine parvovirus infection. Indian Veterinary Journal, 2005, 82(30), 332333.

Bernard $\mathrm{M}$ and Eeintraub, Cardiac abnormalities in Subarachnoid Hemorrhage. Aha J, 2015, 5, 384-392.

Biswas S, Chakrovorty D and Pradhan NR, Clinical and haemato-biochemical changes in parvovirus infection in dogs. Indian Vet. J,2015, 25(1), 16-18.

Chakrabarti A, Textbook of Clinical Veterinary Medicine, IInd edn. 1994, Kalyani Publishers, New Delhi.

Craver LI, Marco MP, Martínez I, Rue M, Borras M, Martin ML, Sarro F, Valdivielso JM and Fernandez E, Mineral metabolism parameters throughout chronic kidney disease stages 1-5--achievement of K/DOQI target ranges. Nephrol Dial Transplant,2007, 22, 1171-1176.

Della PK, Zaki S, Covendir M,Church DB and Malik R, Effectof acute haemorrhage on QRS amplitude of the lead II canine electrocardiogram. Aust. J. of Vet. Medicine, 1999, 13, 9-12.

Dhanapalan P, Srinivasan SR and Gnanaprakashan V, Biochemical and ECG changes in serum electrolyte imbalance in dogs. Indian Vet. J,1993, 13, 9-12.

Dharmadheeran JS, Kumar M and Shukla SK, Monitoring Haematobiochemical parameter in experimental canine parvovirus infection. Indian Vet. J, 2003, 23(1), 9-11.

Ettinger PO, Regan TJ and Oldewurtel HA, Hyperkalemia,cardiac conduction, and the electrocardiogram. Am. Heart 
J,1974, 88: 360-371.

Grigonis A, Macijauskas V and Zamokas G, Examination of liver functions in dogs with parvovirus enteritis.Veterinarianir-Zootechnika, 2002, 17, 23-28.

Hammer I, An introduction to Electrocardiography edn. II Pitman Medical Publishing Co., Ltd., 1978, England.

Jain NC, Veterinary haematology-4thEd. Lea and Febiger Waverly Co, 1986, Philadelphia.

Kline RP, Hanna MS, Dresdner KP and Wit AL, Time courses of changes in intracellular $\mathrm{K}+, \mathrm{Na}+$, and $\mathrm{pH}$ of subendocardial Purkinje cells during the first 24 hours after coronary occlusion. Circu. Res, 1992, 70(3), 566-575.

Lee SY, Lee YS, Choi HM, Ko YS, Lee HY, Jo SK, Cho WY and Kim HK, 2012. Distinct pathophysiologic mechanisms of septic acute kidney injury: role of immune suppression and renal tubular cell apoptosis in murine model of septic acute kidney injury. Crit. Care Med, 2012, 40, 2997-3006.

Mallela MK, Bhutia YD, Suryanarayan C, Rajni B and Reddy MCS, Efficacy of conservative the rapy in managing chronic renal failure in dogs. Indian Vet. J,2006, 26,82-89.

Mohan R, Nauriyal DC and Singh KB, Electrocardiographic alterations in canine parvoviral infection. Indian Vet. J, 1994, 71, 484-488.

Rai A, Nauriyal DC and Rajesh Mohan, A note onhaematological observations in canine parvoviral gastroenteritis. Indian Vet. J, 1994, 13, 99.

Scheel KW and Williams SE, Hypertrophy and coronary and collateral vascularity in dogs with severe chronic anemia. Am. J. of Phys: Heart and Circulatory Physiology, 1985, 5, 1031-1037.

Shah SA, Sood NK, Wani N, Gupta K and Singh A.2013.Haemato-biochemical changes in canine parvoviral infection. Indian Vet. J. Path, 2013, 37(2), 131133.

Tatiana, C.,Cristiane, F.and Glaucia,B.P.2013.Electrocardiographi c evaluationand serum cardiac troponin I levels in anemic dogs with blood parasites.Capa, 34, 2915-2924.

Tilley, L.P.1992. In essentials of canine and feline Electrocardiography,3rd Ed., Lea and Febiger, Philadelphia.

\section{How to cite this article:}

Moneesh Thakur, S.R. Upadhyay and Radhika Thakur. 2018. Electrocardiographic Studies on Extra-Cardiac Affections in Dogs. Int.J.Curr.Microbiol.App.Sci. 7(08): 1101-1114. doi: https://doi.org/10.20546/ijcmas.2018.708.125 